\title{
DOSES E FONTES DE NITROGÊNIO EM PASTAGEM DE CAPIM-MARANDU. II - NUTRIÇÃO NITROGENADA DA PLANTA ${ }^{(1)}$
}

\author{
Kátia Aparecida de Pinho Costa ${ }^{(2)}$, Valdemar Faquin ${ }^{(3)}$, Itamar Pereira de \\ Oliveira $^{(4)}$, Josinaldo Lopes Araújo ${ }^{(5)}$ \& Rodrigo Basílio Rodrigues ${ }^{(6)}$
}

\begin{abstract}
RESUMO
A adubação nitrogenada influencia positivamente no aspecto nutricional das gramíneas forrageiras, a ponto de resultar na recuperação adequada de pastagem. Objetivou-se com este estudo, avaliar a nutrição do capim-marandu, submetido a doses e fontes de $\mathrm{N}$, pela determinação indireta de clorofila e pela concentração de $\mathrm{N}$ total, bem como a relação entre eles e os teores de $\mathrm{N}$ inorgânico $\left(\mathrm{N}_{-} \mathrm{NH}_{4}^{+} \mathrm{e} \mathrm{N}-\mathrm{NO}_{3}^{-}\right)$ nas folhas das plantas por um periodo de três anos. $O$ experimento foi realizado de julho de 2003 a março de 2006, na Fazenda Modelo da UEG, numa área de 882 m²$^{2}$, com pastagem estabelecida há mais de dez anos, com baixa produção de forragem. $O$ delineamento experimental utilizado foi em blocos casualizados, com parcelas subdivididas no tempo, com três repetições. Foi utilizado o esquema fatorial 2 x 4, sendo duas fontes de $\mathrm{N}$ (sulfato de amônio e uréia) e quatro doses de $\mathrm{N}(0,100,200$ e $300 \mathrm{~kg} \mathrm{ha}^{-1}$ ano $\left.^{-1}\right)$. Em cada um dos anos, foram realizados três cortes para avaliação da planta forrageira. Os teores de clorofila aumentaram com as doses de $\mathrm{N}$ e anos de avaliação da pastagem. A maior concentração de $\mathrm{N}$ foi encontrada na maior dose de $\mathrm{N}$ aplicada na forma de sulfato de amônio. Verificou-se uma relação direta entre os teores de clorofila e as concentrações de $\mathrm{N}$ nas folhas recém-expandidas de capim-marandu. $\mathrm{O} \mathrm{N}$ inorgânico $\left(\mathrm{N}^{-} \mathrm{NH}_{4}{ }^{+} \mathrm{e} \mathrm{N-NO}{ }_{3}^{-}\right)$representou pequena fração do $\mathrm{N}$ total das folhas de capim-marandu.
\end{abstract}

Termos de indexação: clorofilômetro, Brachiaria brizantha, estado nutricional, N, SPAD.

\footnotetext{
(1) Parte da Tese de Doutorado da primeira autora, apresentado a Universidade Federal de Lavras, para obtenção do título de Doutor em Ciência do Solo. Recebido para publicação em agosto de 2007 e aprovado em maio de 2008.

(2) Professora da Universidade de Rio Verde - FESURV. E-mail: katiazoo@hotmail.com

(3) Professor Titular, Departamento de Ciência do Solo da Universidade Federal de Lavras - DCS/UFLA. Caixa Postal 37, CEP 37200-000 Lavras (MG). Bolsista CNPq. E-mail: vafaquin@ufla.br

(4) Pesquisador da Embrapa Arroz e Feijão. Santo Antônio de Goiás (GO). E-mail: itamar.agro@yahoo.com.br

${ }^{(5)}$ Mestranda em Solo e Água, Escola de Agronomia, Universidade Federal de Goiás. E-mail: crissolocria@yahoo.com.br

${ }^{(6)}$ Doutorando em Ciência do Solo, Departamento de Ciência do Solo, UFLA. Bolsista CNPq. E-mail: severianoec@yahoo.com.br
} 


\title{
SUMMARY: NITROGEN DOSES AND SOURCES IN MARANDU PASTURES. II - PLANT NITROGEN NUTRITION
}

\begin{abstract}
Nitrogen fertilization positively influences nutritional aspects in grass and can result in largely recovered pastures. The research objective was to study the nutrition of marandu grass treated with nitrogen doses and sources, by methods of indirect determination of chlorophyll (SPAD) and total nitrogen concentration and the relation between them and inorganic nitrogen contents $\left(\mathrm{N}-\mathrm{NH}_{4}{ }^{+}\right.$and $\left.\mathrm{N}-\mathrm{NO}_{3}{ }^{-}\right)$in plant leaves. The experiment was carried out from July of 2003 to March of 2006 on a model farm of the Universidade Estadual de Goiás, in an area of $882 \mathrm{~m}^{2}$. The pasture had been used for more than ten years and the herbage yield was low and considered moderately degraded. A split-plot with three replications was used. The experiment had a complete randomized block, $2 \times 4$ factorial design, with two nitrogen sources (ammonium sulfate and urea) and four nitrogen doses ( 0 , 100,200 , and $300 \mathrm{~kg} \mathrm{ha}^{-1} \mathrm{yr}^{-1}$ ). In each year, marandu grass was cut and evaluated three times. Chlorophyll contents increased owing to the nitrogen doses and over the years. Nitrogen concentration was highest after the application of highest nitrogen doses in form of ammonium sulfate. The chlorophyll content and leaf nitrogen concentration in newly expanded leaves of marandu grass were directly related. Mineral nitrogen concentration $\left(\mathrm{N}-\mathrm{NH}_{4}{ }^{+}\right.$and $\left.\mathrm{N}-\mathrm{NO}_{3}{ }^{-}\right)$represented little total nitrogen fraction of forage lives. Chlorophyll meter can be used for evaluation of nutritional state of marandu grass to know nitrogen absorption. The inorganic nitrogen concentration $\left(\mathrm{N}-\mathrm{NH}_{4}{ }^{+}\right.$and $\left.\mathrm{N}-\mathrm{NO}_{3}{ }^{-}\right)$represented a small fraction of total nitrogen in the forage leaves.
\end{abstract}

Index terms: Brachiaria brizantha, chlorophyll meter, nutritional state, nitrogen, SPAD.

\section{INTRODUÇÃO}

Os capins do gênero Brachiaria são conhecidos desde a década de 50. Entretanto, a verdadeira expansão desse gênero ocorreu nas décadas de 70 e 80 , principalmente nas regiões de clima mais quente. Hoje, provavelmente, ocupa mais de $50 \%$ das áreas de pastagens cultivadas no Brasil tropical, devido à sua adaptação às mais variadas condições de solo e clima, e vem ocupando espaços cada vez maiores nos cerrados, com vantagens sobre outras espécies, propiciando produções satisfatórias de forragem (Soares Filho, 1994). Dentre as espécies, destaca-se a Brachiaria brizantha cv. Marandu, que adquiriu uma grande expressividade nas áreas de pastagens cultivadas e, por essa razão, tornou-se uma das plantas forrageiras mais detalhadamente estudadas no Brasil (Silva, 2004).

Diante disso, tem crescido a preocupação com a melhoria da fertilidade do solo e o manejo adequado dessa forrageira, devido ao aumento da área de pastagens degradadas, considerado um dos maiores problemas da pecuária. Estima-se que cerca de $80 \%$ dos 45 a 50 milhões de hectares da área de pastagens nos cerrados encontram-se em algum estádio de degradação (Barcellos, 1996). Isso remete a uma preocupação muito grande, principalmente porque o Brasil, pela extensão da sua área territorial e pelas condições climáticas favoráveis, apresenta enorme potencial de produção bovina em pasto. Assim, o fornecimento de nutrientes, em quantidades e proporções adequadas, particularmente o $\mathrm{N}$, assume grande importância no processo produtivo de pastagens (Fagundes et al., 2006).

Primavesi et al. (2005) relatam que, de todos os nutrientes minerais, o $\mathrm{N}$ é quantitativamente o mais importante para o crescimento da planta. A forma de fertilizantes nitrogenados usados na adubação pode influenciar o balanço entre cátions e ânions nas plantas (Engels \& Marschner, 1995). Diante disso, as plantas diferem-se na sua preferência pelas formas de $\mathrm{N}$, absorvendo-o primariamente em formas inorgânicas como $\mathrm{N}-\mathrm{NO}_{3}{ }^{-}$e $\mathrm{N}-\mathrm{NH}_{4}{ }^{+}$via sistema radicular (Williams \& Miller, 2001). Em solos calcareados e aerados, o N-NO ${ }_{3}{ }^{-}$é a principal forma de $\mathrm{N}$ mineral disponível para o crescimento das plantas, enquanto, em caso de acidez e de inundação, o N- $\mathrm{NH}_{4}{ }^{+}$é predominante (Raij, 1991).

O estado nutricional das plantas é avaliado, primordialmente, pela análise química do tecido vegetal, tendo como aplicações a identificação de deficiências nutricionais e a predição da necessidade do suprimento de nutrientes. A determinação indireta do teor de clorofila na folha, empregando-se o clorofilômetro, pode ser utilizada na quantificação de N (Mengel \& Kirkby, 2001). Várias pesquisas têm mostrado aumento no teor de clorofila da folha, com incremento das doses de $\mathrm{N}$ em espécies do gênero Brachiaria e correlações positivas entre o teor de clorofila e concentração de N na folha (Santos Jr. \& Monteiro, 2003; Bonfim-da-Silva, 2005; Lavres Jr. \& Monteiro, 2006; Batista, 2006). 
Diante desse contexto, objetivou-se, com este estudo, avaliar a nutrição do capim-marandu, submetido a doses e fontes de $\mathrm{N}$, pela determinação indireta de clorofila e pela concentração de $\mathrm{N}$ total, bem como a relação entre eles e os teores de $\mathrm{N}$ inorgânico ( $\mathrm{N}^{-} \mathrm{NH}_{4}^{+}$e N-NO$\left.{ }_{3}^{-}\right)$nas folhas das plantas por um período de três anos.

\section{MATERIAL E MÉTODOS}

O experimento foi realizado de julho de 2003 a março de 2006, na Fazenda Modelo do Curso de Zootecnia da Universidade Estadual de Goiás, em São Luís de Montes Belos-GO, a 579 m de altitude, $16^{\circ} 31$ ' 30 " de latitude sul e 5022 ' 20 " de longitude oeste. A área de pastagem utilizada foi de $882 \mathrm{~m}^{2}$, dividida em três blocos de $294 \mathrm{~m}^{2}$, com parcelas de $20 \mathrm{~m}^{2}$ e área útil de $6 \mathrm{~m}^{2}$. A pastagem já se encontrava estabelecida há mais de dez anos, em estádio moderado de degradação, apresentando pouca cobertura do solo, com baixa produção de forragem, devido à exploração intensiva de animais e falta de reposição de nutrientes no solo.

O delineamento experimental utilizado foi em blocos casualizados com parcelas subdivididas no tempo, com três repetições. Foi utilizado o esquema fatorial $2 \times 4$, sendo duas fontes de $\mathrm{N}$ (sulfato de amônio e uréia) e quatro doses de $\mathrm{N}\left(0,100,200\right.$ e $300 \mathrm{~kg} \mathrm{ha}^{-1}$ $\mathrm{ano}^{-1}$ ).

O solo foi classificado como Latossolo Vermelho distrófico (Embrapa, 2006), de textura argilosa, cujas médias das características químicas de todas as parcelas, na profundidade de $0-20 \mathrm{~cm}$, estão apresentadas no quadro 1. A metodologia utilizada para a análise de solo foi a descrita por Silva (1999).

Quadro 1. Características químicas do solo avaliadas antes da aplicação dos tratamentos em 2003, 2004 e 2005

\begin{tabular}{|c|c|c|c|}
\hline Característica & 2003 & 2004 & 2005 \\
\hline $\mathrm{pH}\left(\mathrm{CaCl}_{2}\right)$ & 5,2 & 5,1 & 4,6 \\
\hline $\mathrm{Al}^{3+}\left(\mathrm{cmol}_{\mathrm{c}} \mathrm{dm}^{-3}\right)$ & 0,0 & 0,1 & 0,2 \\
\hline P-Mehlich - $1\left(\mathrm{mg} \mathrm{dm}^{-3}\right)$ & 1,3 & 6,4 & 1,8 \\
\hline $\mathrm{K}^{+}\left(\mathrm{cmol}_{\mathrm{c}} \mathrm{dm}^{-3}\right)$ & 0,42 & 0,23 & 0,11 \\
\hline $\mathrm{Ca}^{2+}\left(\mathrm{cmol}_{\mathrm{c}} \mathrm{dm}^{-3}\right)$ & 2,70 & 2,79 & 2,20 \\
\hline $\mathrm{Mg}^{2+}\left(\mathrm{cmol}_{\mathrm{c}} \mathrm{dm}^{-3}\right)$ & 1,00 & 0,91 & 0,23 \\
\hline $\mathrm{H}+\mathrm{Al}\left(\mathrm{cmol}_{\mathrm{c}} \mathrm{dm}^{-3}\right)$ & 3,9 & 5,3 & 3,5 \\
\hline $\mathrm{CTC}\left(\mathrm{cmol}_{\mathrm{c}} \mathrm{dm}-3\right)$ & 8,0 & 8,23 & 6,5 \\
\hline $\mathrm{SO}_{4}^{2-}\left(\mathrm{mg} \mathrm{dm}^{2}\right)$ & 9,8 & 18,9 & 30,0 \\
\hline $\mathrm{Cu}(\mathrm{mg} \mathrm{dm}-3)$ & 0,4 & 1,7 & 1,0 \\
\hline $\mathrm{Zn}(\mathrm{mg} \mathrm{dm}-3)$ & 0,2 & 2,9 & 0,7 \\
\hline $\mathrm{Fe}\left(\mathrm{mg} \mathrm{dm} \mathrm{m}^{-3}\right)$ & 13,0 & 30,0 & 31,3 \\
\hline $\operatorname{Mn}\left(\mathrm{mg} \mathrm{dm}^{-3}\right)$ & 27,4 & 41,0 & 15,6 \\
\hline $\mathrm{MO}\left(\mathrm{g} \mathrm{dm}^{-3}\right)$ & 11,0 & 18,0 & 20,0 \\
\hline
\end{tabular}

No primeiro ano (2003) foram aplicados $500 \mathrm{~kg} \mathrm{ha}^{-1}$ de calcário dolomítico com $85 \%$ de PRNT a lanço, 60 dias antes do período chuvoso. Em setembro, após as primeiras chuvas, foram aplicados $150 \mathrm{~kg} \mathrm{ha}^{-1} \mathrm{de}_{2} \mathrm{O}_{5}$, $80 \mathrm{~kg} \mathrm{ha}^{-1}$ de $\mathrm{K}_{2} \mathrm{O}$ e $30 \mathrm{~kg} \mathrm{ha}^{-1}$ de FTE BR-12, utilizando como fontes superfosfato simples, cloreto de potássio e fritas, respectivamente. A partir dos resultados da análise em amostra de solo do segundo ano (2004), foi realizada adubação de manutenção com $50 \mathrm{~kg} \mathrm{ha}^{-1} \mathrm{de}_{2} \mathrm{O}_{5}$ e $100 \mathrm{~kg} \mathrm{ha}^{-1}$ de $\mathrm{K}_{2} \mathrm{O}$, provenientes das fontes de superfosfato simples e cloreto de potássio, respectivamente. No terceiro ano de recuperação (2005), foram aplicados $150 \mathrm{~kg} \mathrm{ha}^{-1}$ de $\mathrm{P}_{2} \mathrm{O}_{5}, 120 \mathrm{~kg} \mathrm{ha}^{-1} \mathrm{de}$ $\mathrm{K}_{2} \mathrm{O}$ e $20 \mathrm{~kg} \mathrm{ha}^{-1}$ de FTE BR-12, na forma de superfosfato simples, cloreto de potássio e fritas, respectivamente. A adubação de manutenção foi realizada de acordo com Sousa \& Lobato (2004), sendo toda adubação realizada com uma única aplicação a lanço no início do período chuvoso (setembro), antes dos fertilizantes nitrogenados.

A adubação nitrogenada, em cada ano, foi parcelada em três épocas, após cada corte de avaliação da forrageira. A primeira aplicação foi realizada em dezembro, a segunda em janeiro, e a terceira em fevereiro, todas com intervalo de 30 dias.

A planta forrageira foi coletada com auxílio de um quadrado de ferro de $1 \times 1 \mathrm{~m}$ e cortada com tesoura de aço à altura de $20 \mathrm{~cm}$ da superfície do solo. Após cada corte de avaliação, foi realizado o corte de uniformização de toda a área experimental na mesma altura de corte das plantas avaliadas, sendo retirado da área o resíduo dessa uniformização.

O material coletado no campo foi acondicionado em sacos plásticos e enviado ao laboratório, onde foi retirada uma amostra representativa de cada parcela, de aproximadamente $500 \mathrm{~g}$. Posteriormente, o material foi colocado em estufa de ventilação forçada de ar, com temperatura entre 58 e $65^{\circ} \mathrm{C}$ por $72 \mathrm{~h}$, para secagem. Posteriormente, as amostras foram moídas em moinho do tipo Wiley, passadas em peneira de $1 \mathrm{~mm}$ e armazenadas em sacos plásticos.

Para estimar o teor de clorofila nas folhas, utilizouse clorofilômetro SPAD-502 (Soil and Plant Analysis Development). As leituras foram realizadas no campo em seis lâminas de folhas recém-expandidas, no sentido do ápice para a base da planta, de cada parcela experimental, sendo consideradas cinco leituras por folha, totalizando 30 leituras em cada tratamento. As leituras foram realizadas um dia antes do primeiro, do segundo e do terceiro corte de avaliação da planta forrageira. Nessas mesmas folhas, foi realizada análise química de $\mathrm{N}$ total, pelo método semimicro Kjeldahl (Malavolta et al., 1997). Para a determinação dos teores de amônio $\left(\mathrm{N}-\mathrm{NH}_{4}{ }^{+}\right)$e nitrato $\left(\mathrm{N}-\mathrm{NO}_{3}{ }^{-}\right)$, pesou-se $0,1 \mathrm{~g}$ de material vegetal seco, onde foram determinados por colorimetria, de acordo com o método de Tedesco et al. (1985).

Todas as variáveis receberam o tratamento estatístico pelo software SISVAR 4.6 (Ferreira, 2000). 
Foi realizada a análise de variância e, em função da significância para as variáveis, foram ajustadas equações de regressão, com nível de significância de $5 \%$.

\section{RESULTADOS E DISCUSSÃO}

A análise de variância não mostrou efeito significativo da interação doses $\mathrm{x}$ fontes de $\mathrm{N}$ para o teor de clorofila. Entretanto, houve efeito significativo de doses de $\mathrm{N}$ e anos avaliados. Nos três anos de avaliação, houve ajuste quadrático entre os teores de clorofila e as doses de N. A dose de N de $300 \mathrm{~kg} \mathrm{ha}^{-1}$ proporcionou os maiores teores de clorofila em todos os anos (Figura 1). Nas doses máximas de N, foram verificados teores de clorofila de 44,23, 45,03, e 46,14 unidades $\mathrm{SPAD}$, mostrando aumento em relação à nãoaplicação de $\mathrm{N}$ de 27,28 , e $30 \%$ para 2004, 2005 e 2006 , respectivamente. Ressalta-se que a resposta da forrageira em produção de massa seca foi linear em função das doses de N aplicadas (Costa, 2007).

Os teores de clorofila nas lâminas de folhas recémexpandidas de capim-marandu foram estudados por Abreu \& Monteiro (1999), que observaram que, aos 14, 28 e 42 dias de crescimento da forrageira, os teores de clorofila variaram entre 31, 18 e 14 unidades SPAD para a não-aplicação de $\mathrm{N}$ e entre 51, 57 e 46 unidades SPAD para a dose máxima de $\mathrm{N}$, respectivamente. Mattos \& Monteiro (2003), trabalhando com doses de N e S em um Neossolo Quartzarênico, na recuperação do capim-braquiária, verificaram aumento do teor de clorofila com o aumento da dose de $\mathrm{N}$.

Segundo Bullock \& Anderson (1998), mais clorofila é sintetizada com o aumento da disponibilidade de $\mathrm{N}$ para a planta, resultando em aumento da intensidade do verde nas folhas. Porém, esse aumento de clorofila atinge um patamar denominado ponto de maturidade fotossintético, que se mantém invariável, mesmo com aumento dos teores de N no tecido da planta (Schepers et al., 1992; Costa et al., 2001). Esse fato ocorreu neste trabalho (Figura 1), em que se observou, nos três anos avaliados, que, a partir da dose de $200 \mathrm{~kg} \mathrm{ha}^{-1}$ $\mathrm{ano}^{-1} \mathrm{de} \mathrm{N}$, os teores de clorofila tenderam a se estabilizar.

Não foi observada significância para a interação doses de $\mathrm{N} \mathrm{x}$ anos na concentração de $\mathrm{N}$ nas folhas onde foram realizadas as leituras de SPAD. No entanto, foi observado efeito significativo da interação doses $\mathrm{x}$ fontes de N (Figura 2). Observou-se aumento quadrático na concentração do $\mathrm{N}$ em função das doses de ambas as fontes, mostrando aumento em relação à dose zero de $48 \%$ para sulfato de amônio e $46 \%$ para uréia, indicando o baixo suprimento natural de $\mathrm{N}$ do solo. Com as maiores doses, as plantas adubadas com sulfato de amônio apresentaram maior concentração de $\mathrm{N}$ do que aquelas adubadas com uréia, mostrando aumento nas doses máximas de 5,8\%, que pode ser devido à menor perda de $\mathrm{N}$ por volatilização de $\mathrm{NH}_{3}$ do sulfato de amônio aplicado em superfície (Cantarella et al., 2001).

Em estudo de doses de $\mathrm{N}$ e $\mathrm{S}$ na recuperação de pastagem de Brachiaria brizantha cv. Marandu, em Neossolo Quartzarênico, Oliveira et al. (2005) verificaram aumento da concentração de $\mathrm{N}$ na parte aérea da planta à medida que ocorreu aumento no fornecimento do nutriente. Resultado similar foi obtido por Campos (2004), que, ao estudar a fertilização com sulfato de amônio em um solo sob pastagens, observou que a concentração de N na parte aérea do capimbraquiária aumentou linearmente com as doses de N.

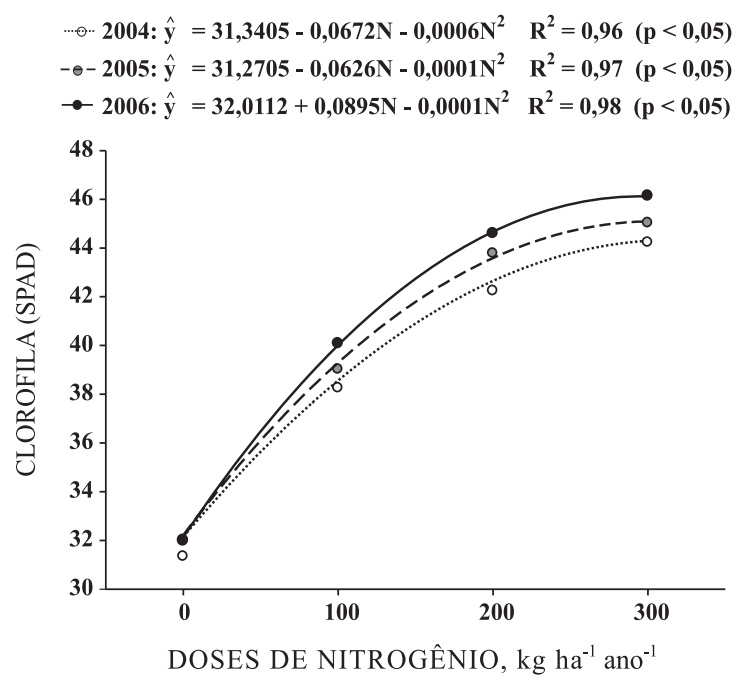

Figura 1. Teores de clorofila (unidades SPAD) na folha de capim-marandu em função de doses de nitrogênio, avaliados em 2004, 2005 e 2006 (média de três cortes por ano).

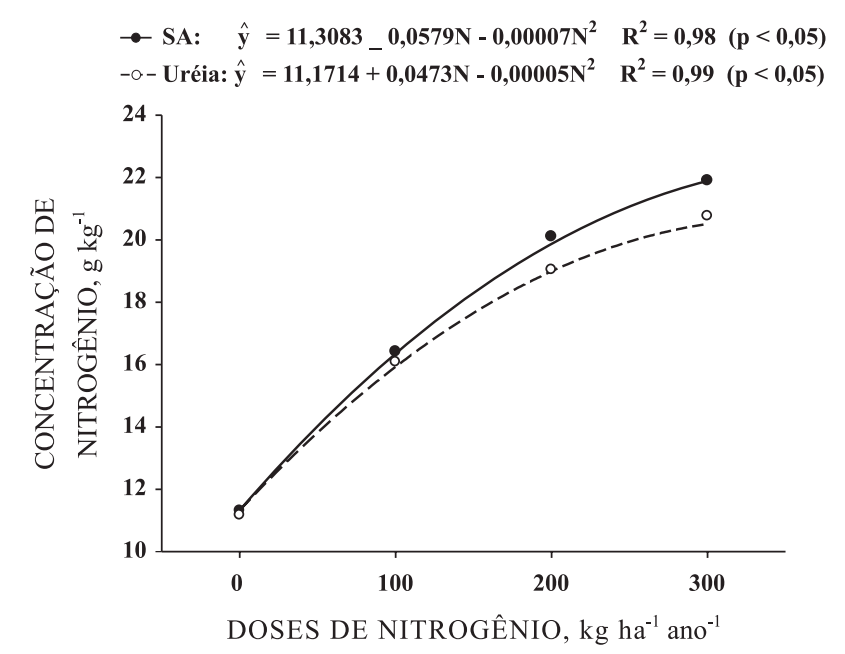

Figura 2. Concentração de nitrogênio nas lâminas de folhas recém-expandidas do capim-marandu, em função de doses de nitrogênio aplicadas na forma de sulfato de amônio e de uréia (média de três cortes por ano). 
A figura 3 mostra uma relação direta entre o teor de clorofila e a concentração de $\mathrm{N}$ total nas folhas recém-expandidas do capim-marandu. Abreu \& Monteiro (1999) relatam que essa relação pode ser linear até que o $\mathrm{N}$ não seja mais assimilado e seja acumulado na forma de nitrato, tendendo à estabilização da intensidade do verde. Além de o $\mathrm{N}$ ser componente da molécula da clorofila, 50 a $70 \%$ do $\mathrm{N}$ total das folhas é integrante de proteínas e enzimas associadas aos cloroplastos (Chapman \& Barreto, 1997).

Várias pesquisas têm mostrado relações diretas entre o teor de clorofila determinado pelo clorofilômetro e a concentração de $\mathrm{N}$ em gramíneas forrageiras, demonstrando que essa determinação é promissora para avaliar o estado nutricional das plantas em relação ao N (Colozza et al., 2000; Santos Jr. \& Monteiro, 2003; Lavres Jr. \& Monteiro, 2006).

Não houve efeito significativo da interação doses $\mathrm{x}$ fontes de $\mathrm{N}$ na concentração de amônio (N$\mathrm{NH}_{4}^{+}$) no tecido das folhas em que foram realizadas as leituras de SPAD. Entretanto, foi observado efeito significativo da interação doses de $\mathrm{N} x$ anos. Observase, na figura 4, que o incremento das doses de $\mathrm{N}$ em todos os anos avaliados aumentou o teor foliar de N$\mathrm{NH}_{4}{ }^{+}$de forma linear. As médias ajustadas na maior dose foram de 1,91, 1,93, e 2,05 $\mathrm{mg} \mathrm{kg}^{-1}$, mostrando aumento de 73,69 , e $50 \%$ em relação à não-aplicação de N, em 2004, 2005 e 2006, respectivamente. O maior teor de amônio foi verificado em 2006, mostrando aumento na maior dose de $6,8 \%$ em relação a 2004 e $5,9 \%$ em 2005.

As fontes de $\mathrm{N}$ e os anos avaliados não influenciaram nos teores de $\mathrm{N}^{-\mathrm{NO}_{3}}{ }^{-}$na planta, havendo efeito significativo apenas para doses de N. $\mathrm{O}$ teor de $\mathrm{N}^{-\mathrm{NO}_{3}}{ }_{3}^{-}$aumentou de forma linear com o acréscimo das doses de N (Figura 5), mostrando aumento de 69 \% na maior dose aplicada em relação à não-aplicação de $\mathrm{N}$.

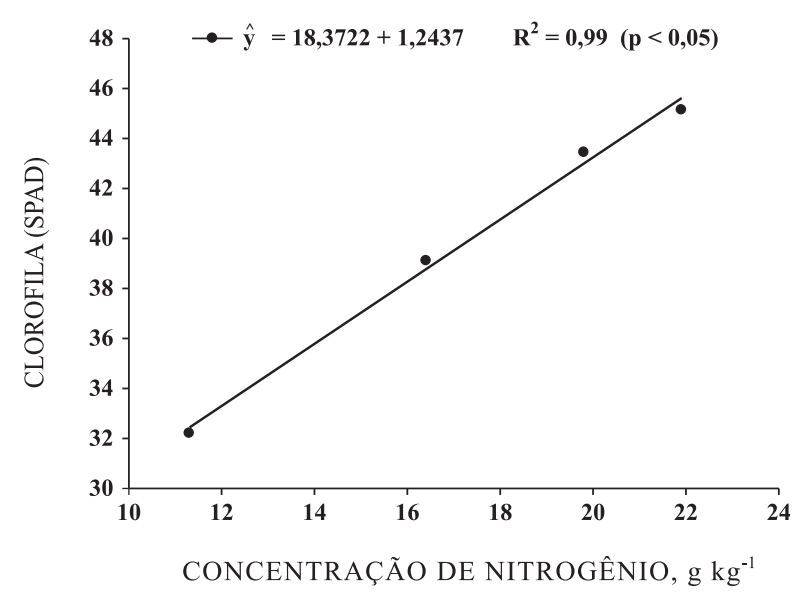

Figura 3. Relação entre o teor de clorofila e a concentração de nitrogênio total nas lâminas de folhas recém-expandidas do capim-marandu.
Em estudo com doses e fontes de N no capimmarandu, Primavesi et al. (2006) encontraram teores de $\mathrm{N}^{-\mathrm{NO}_{3}}{ }_{3}^{-}$de $223 \mathrm{mg} \mathrm{kg}^{-1}$ para a não-aplicação de $\mathrm{N}$ e de $709 \mathrm{mg} \mathrm{kg}^{-1}$ para a dose máxima e o maior teor foi verificado na fonte de nitrato de amônio. Os teores de $\mathrm{N}_{-} \mathrm{NO}_{3}{ }_{3}^{-}$encontrados no tecido do capim-marandu estão dentro dos padrões normais, pois o limite de teores tóxicos para os animais está entre $243 \mathrm{e}$ $321 \mathrm{mmol}_{\mathrm{c}} \mathrm{kg}^{-1} \mathrm{de} \mathrm{NO}_{3}{ }^{-}(0,34$ a $0,45 \%$ de $\mathrm{N}$ na forma de $\mathrm{NO}_{3}^{-}$), ou seja, de 3.400 a $4.500 \mathrm{mg} \mathrm{kg}^{-1} \mathrm{de} \mathrm{NO}_{3}{ }^{-}$ na forragem fresca (Whitehead, 1995). Mesmo nas maiores doses de N, esses teores e os relatados por Primavesi et al. (2005) estão bem abaixo do limite tóxico, indicando boa metabolização de $\mathrm{N}$ pela planta, confirmada pela grande produção de matéria seca (Costa, 2007).

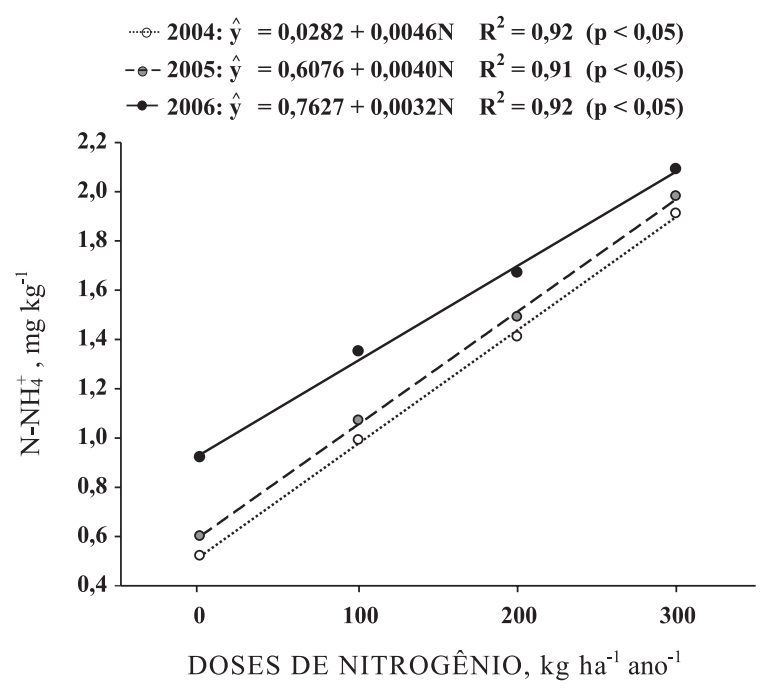

Figura 4. Teores de $\mathrm{N}^{-\mathrm{NH}_{4}}{ }^{+}$nas folhas de capimmarandu em função de doses de nitrogênio, avaliadas em 2004, 2005 e 2006 (média de três cortes por ano).

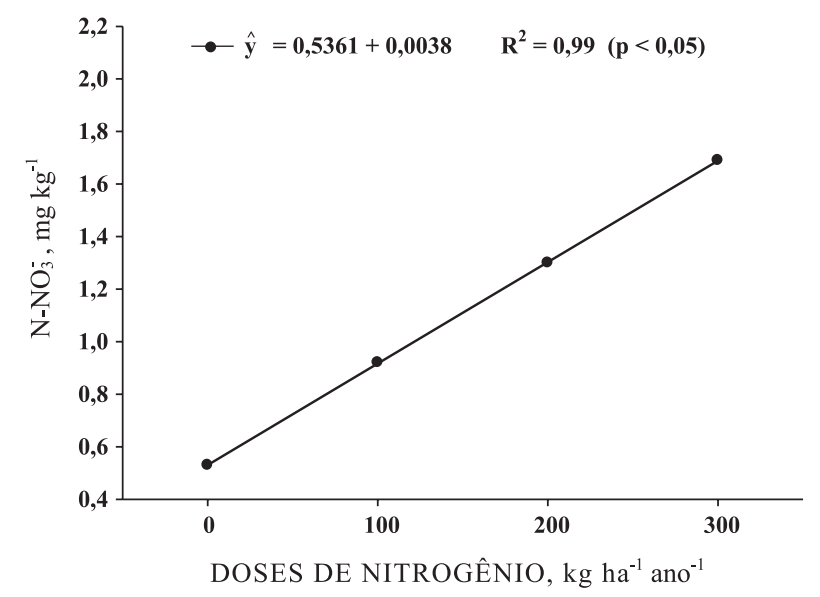

Figura 5. Teores de $\mathrm{N}-\mathrm{NO}_{3}{ }^{-}$na folha do capimmarandu em função de doses de nitrogênio (média de três cortes por ano). 
Independente do ano e das fontes de $\mathrm{N}$ utilizadas, os teores de N-NH${ }_{4}{ }^{+}$foram superiores aos de $\mathrm{N}-\mathrm{NO}_{3}{ }^{2}$ no tecido da planta do capim-marandu. Esses resultados evidenciam que houve redução no processo de nitrificação do $\mathrm{NH}_{4}{ }^{+}$no solo. Isto pode ser explicado pela diminuição do $\mathrm{pH}$ (Costa et al., 2008) em razão de altas doses de $\mathrm{N}$ em fontes acidificantes (sulfato de amônio e uréia), inibindo, assim o processo de nitrificação. Bissani et al. (2004) explicam que em $\mathrm{pH}$ baixo a nitrificação é afetada devido à especialização das bactérias nitrificadoras, que exigem $\mathrm{pH}$ mais elevado. Em clima seco ou pH baixo, a nitrificação pode paralisar-se bem antes da mineralização.

Esses resultados corroboram os encontrados por Primavesi et al. (2005), que, trabalhando com doses e fontes de $\mathrm{N}$ no capim-coastcross, verificaram que as plantas absorveram mais $\mathrm{N}_{-} \mathrm{NO}_{3}{ }^{-}$do que $\mathrm{N}-\mathrm{NH}_{4}{ }^{+}$em ambas as fontes utilizadas, devido ao alto $\mathrm{pH}$ inicial do solo, provocando uma rápida nitrificação do $\mathrm{N}_{-} \mathrm{NH}_{4}^{+}$, proveniente tanto do nitrato de amônio quanto da uréia.

\section{CONCLUSÕES}

1. Os teores de clorofila aumentaram com as doses de $\mathrm{N}$ e anos de avaliação da pastagem.

2. A maior concentração de $\mathrm{N}$ foi verificada na maior dose de $\mathrm{N}$ aplicada na forma de sulfato de amônio.

3. Foi verificada uma relação direta entre os teores de clorofila e as concentrações de N nas folhas recémexpandidas de capim-marandu.

4. O N inorgânico $\left(\mathrm{N}^{-} \mathrm{NH}_{4}{ }^{+} \mathrm{e} \mathrm{N}-\mathrm{NO}_{3}{ }^{-}\right)$representou pequena fração do $\mathrm{N}$ total das folhas de capimmarandu.

\section{LITERATURA CITADA}

ABREU, J.B.R. \& MONTEIRO, F.A. Produção e nutrição do capim-marandu em função de adubação nitrogenada e estádios de crescimento. B. Ind. Animal, 56:37-146, 1999.

BARCELLOS, A.O. Sistemas extensivos e semi-intensivos de produção: pecuária bovina de corte nos cerrados. In SIMPÓSIO SOBRE O CERRADO. BIODIVERSIDADE E PRODUÇÃO SUSTENTÁVEL DE ALIMENTOS E FIBRAS NOS CERRADOS, Brasília, 1996. Anais. Brasília, 1996. p.130-136.

BATISTA, K. Nitrogênio e enxofre na implantação do capimmarandu em substituição ao capim-braquiária em degradação num solo com baixa matéria orgânica. Piracicaba, Escola Superior de Agricultura Luiz de Queiroz, 2006. 125p. (Tese de Doutorado)

BISSANI, C.A.; GIANELLO, C.; TEDESCO, M.J. \& CAMARGO, F.A.D.O. Fertilidade dos solos e manejo da adubação de culturas. Porto Alegre, Gênesis, 2004. 328p.
BONFIM-DA-SILVA, E.M. Nitrogênio e enxofre na recuperação de capim-braquiária em degradação em Neossolo Quartzarênico com expressiva matéria orgânica. Piracicaba, Escola Superior de Agricultura Luiz de Queiroz, 2005. 123p. (Tese de Doutorado)

BULLOCK, D.G. \& ANDERSON, D.S. Evaluation of the Minolta SPAD-502 chlorophyll meter for nitrogen management in corn. J. Plant Nutr., 21:741-755, 1998.

CAMPOS, A.X. Fertilização com sulfato de amônio na cultura do milho em um solo do cerrado de Brasília sob pastagem de Brachiaria decumbens. Piracicaba, Escola Superior de Agricultura Luiz de Queiroz, 2004. 199 p. (Tese de Doutorado)

CANTARELLA, H.; CORRÊA, L.; PRIMAVESI, A.C.; FREITAS, A.R. \& SILVA, A.G. Ammonia losses by volatilization from coastcross pasture fertilized with two nitrogen sources. In: INTERNATIONAL GRASSLAND CONGREss, 19., São Pedro, 2001. Proceedings. Piracicaba, FEALQ, 2001. p.190-192.

CHAPMAN, S.C. \& BARRETO, H.J. Using a chlorophyll meter to estimate specific leaf nitrogen of tropical maize during vegetative growth. Agron. J., 89:557-562, 1997.

COLOZZA, M.T.; KIEHL, J.C.; WERNER, J.A. \& SCHAMMASS, E.A. Respostas de Panicum maximum cultivar Aruana a doses de nitrogênio. B. Ind. Animal, 57:21-32, 2000.

COSTA, C.; DWYER, L.M.; DUTILLEUL, P.; STEWART, D.W.; MA, B.L. \& SMITH, D.L. Inter-relationships of applied nitrogen, spad, and yield of leafy and non-leafy maize genotypes. J. Plant. Nutr., 24:1173-1194, 2001.

COSTA, K.A.P. Doses e fontes de nitrogênio na recuperação de pastagem de capim-marandu em solo de cerrado. Lavras, Universidade Federal de Lavras, 2007. 95p. (Tese de Doutorado)

COSTA, K.A.P.; FAQUIN, V.; OLIVEIRA, I.P.; RODRIGUES, C. \& SEVERIANO, E.C. Doses e fontes de nitrogênio em pastagem de capim-marandu. I - Alterações nas características químicas do solo. R. Bras. Ci. Solo, 32:15911599, 2008

EMPRESA BRASILEIRA DE PESQUISA AGROPECUÁRIA EMBRAPA. Centro Nacional de Pesquisa de Solos. Sistema brasileiro de classificação de solos. 2.ed. Rio de Janeiro, 2006. 306p.

ENGELS, C. \& MARSCHNER, H. Plant uptake and utilization of nitrogen. In: BACON, P.E., ed. Nitrogen fertilization in the environment. New York, Marcel Dekker, 1995. p.41-81.

FAGUNDES, J.L.; FONSECA, D.M.; MORAIS, R.V.; MISTURA, C.; VITOR, C.M.T.; GOMIDE, J.A.; NASCIMENTO JUNIOR, D.; SANTOS, M.E.R. \& LAMBERTUCCI, D.M. Avaliação das características estruturais do capimbraquiária em pastagens adubadas com nitrogênio nas quatro estações do ano. R. Bras. Zootec., 35:30-37, 2006. 
FERREIRA, D.F. Análises estatísticas por meio do SISVAR para Windows versão 4.0. In: REUNIÃO ANUAL DA REGIÃO BRASILEIRA DA SOCIEDADE INTERNACIONAL DE BIOMETRIA, São Carlos, 2000. Anais. São Carlos, Universidade Federal de São Carlos, 2000. p.255-258.

LAVRES Jr. J. \& MONTEIRO, F.A. Diagnose nutricional de nitrogênio no capim-aruana em condições controladas. R. Bras. Ci. Solo, 30:829-837, 2006.

MALAVOLTA, E.; VITTI, G.C. \& OLIVEIRA, S.A. Avaliação do estado nutricional das plantas: princípios e aplicações. 2.ed. Piracicaba, Associação Brasileira da Potassa e do Fosfato, 1997. 319p.

MATTOS, W.T. \& MONTEIRO, F.A. Produção e nutrição de capim-braquiária em função de doses de nitrogênio e enxofre. B. Ind. Animal, 60:1-10, 2003.

MENGEL, K. \& KIRKBY, E. Principles of plant nutrition. 5.ed. Dordrecht/Boston/London, Kluwer Academic Publishers, 2001. 849p.

OLIVEIRA, P.P.A.; TRIVALIN, P.C.O.; OLIVEIRA, W.S. \& CORSI, M. Fertilização com nitrogênio e enxofre na recuperação de pastagem de Brachiaria brizantha cv. Marandu em Neossolo quartzarênico. R. Bras. Zootec., 34:1121-1129, 2005.

PRIMAVESI, A.C.; PRIMAVESI, O.; CORREAA, L.A.; CANTARELLA, H. \& SILVA, A.G. Absorção de cátions e ânions pelo capim-coastcross adubado com uréia e nitrato de amônio. Pesq. Agropec. Bras., 40:247-253, 2005.

PRIMAVESI, A.C.; PRIMAVESI, O.; CORRÊA, L.A.; SILVA, A.G. \& CANTARELLA, H. Nutrientes na fitomassa de capim-marandu em função de fontes e doses de nitrogênio. Ci Agrotec., 30:562-568, 2006.

RAIJ, B.van. Avaliação da fertilidade do solo. 2.ed. Piracicaba, Potafos, 1991. 142p
SANTOS Jr., J.D.G. \& MONTEIRO, F.A. Nutrição em nitrogênio do capim-marandu submetido a doses de nitrogênio e idades de crescimento. B. Ind. Animal, 60:139146, 2003.

SCHEPERS, J.S.; FRANCIS, D.D.; VIGIL, M. \& BELOW, F.E. Comparison of corn leaf nitrogen concentration and chlorophyll meter readings. Comm. Soil Sci. Plant Anal., 23:2173-2187, 1992.

SILVA, F.C. Manual de análises químicas de solos, plantas e fertilizantes. Brasília, Embrapa Solos, Embrapa Informática Agropecuária, 1999. 370p.

SILVA, S.C. Fundamentos para o manejo do pastejo de plantas forrageiras dos gêneros Brachiaria e Panicum. In: SIMPÓSIO SOBRE MANEJO ESTRATÉGICO DA PASTAGEM, 2., Viçosa, MG, 2004. Anais. Viçosa, MG, 2004. p.347-385.

SOARES FILHO, C.V. Recomendação de espécie e variedade de Brachiaria para diferentes condições, In: SIMPÓSIO SOBRE MANEJO DE PASTAGEM, 11., Piracicaba, 1994. Anais. Piracicaba, FEALQ, 1994. p.25-48.

SOUSA, D.M.G. \& LOBATO, E. Cerrado: correção do solo e adubação. 2.ed. Brasília, Embrapa Informação Tecnológica, 2004. 416p.

TEDESCO, M.J.; VOLKWEISS, S.J. \& BOHNEN, H. Análises de solo, plantas e outros materiais. Porto Alegre, Universidade Federal do Rio Grande do Sul, 1985. 95p. (Boletim Técnico, 5)

WHITEHEAD, D.C. Grassland nitrogen. Wallingford, CAB International, 1995. 397p.

WILLIAMS, L.E. \& MILLER, A.J. Transporters responsible for the uptake and partitioning of nitrogenous solutes. Ann. Rev. Plant Physiol. Plant Molec. Biol., 52:59-688, 2001. 